\title{
The Conflict in East Ukraine: A Growing Need for Addiction Research and Substance Use Intervention for Vulnerable Populations
}

ISSN: 2578-0042

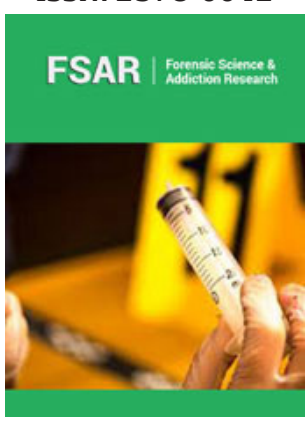

*Corresponding author: Timothy B Erickson, Division of Medical Toxicology, Department of Emergency Medicine, Brigham Health, Harvard Medical School, USA

Submission: 眥January 06, 2020

Published: 眥January 21, 2020

Volume 5 - Issue 3

How to cite this article: Sonny S Patel, Oleksandr Zvinchuk, Timothy B Erickson. The Conflict in East Ukraine: A Growing Need for Addiction Research and Substance Use Intervention for Vulnerable Populations. Forensic Sci Add Res. 5(3). FSAR.000616.2020.

DOI: $10.31031 /$ FSAR.2020.05.000616

Copyright@ Timothy B Erickson, This article is distributed under the terms of the Creative Commons Attribution 4.0 International License, which permits unrestricted use and redistribution provided that the original author and source are credited.

\author{
Sonny S Patel ${ }^{1,2}$, Oleksandr Zvinchuk ${ }^{3}$ and Timothy B Erickson*2,4 \\ ${ }^{1}$ Department of Global Health and Population, USA \\ ${ }^{2}$ Harvard Humanitarian Initiative, USA \\ ${ }^{3}$ Fulbright Visiting Scholar, USA \\ ${ }^{4}$ Department of Emergency Medicine, Brigham Health, Harvard Medical School, USA
}

\begin{abstract}
Security and trauma challenges in Ukraine have been constantly evolving since the 2014 Russian military incursion of Crimea and War in Donbass. One long-term consequence of the conflict in East Ukraine is the toll of substance and alcohol use and addictions that may have been triggered by the conflict among the veterans, internally displaced peoples, and civilian survivors. Further funding and research on substance and alcohol addiction with these vulnerable populations affected by the ongoing Ukrainian conflict should be examined. Are people from fragile states and conflict zones more susceptible to co-morbidity with substance abuse and addiction?
\end{abstract}

\section{Introduction}

The conflict in Ukraine and its human toll since 2014 has reached over 13,000 deaths, nearly 3,000 of which were civilians lost largely to artillery and mines [1]. Recent statistics also estimate that there are over 1.5 million internally displaced people or migrants as a result of the war (Figure 1). Efforts are being made in Ukraine by public and private organizations to improve the situation for Ukrainians who have been affected by the conflict. International support and aid have been increasing since 2014. For example, North Atlantic Treaty Organization (NATO) have increased projects and activities in Ukraine. Through the NATO Science for Peace and Security Programme, Ukraine has been featured in advanced research workshops, advanced training courses, and a larger cooperation with research and development projects. In 2018, Advanced Research Workshop on Health and Environment in Ukrainian Conflict Zones showcased various work in the fields of health, ecology, and economics, which included presentations on the growing concern of substance use arising from the conflict [2]. What may be undermeasured and left unexamined however, is the toll of substance and alcohol uses and addictions that may have been triggered by the conflict among the veterans, internally displaced peoples, and civilian survivors. Conflicts and wars are known to contribute to a higher burden of mental health problems among specific individuals who experience trauma as well as among those living in or near to conflict zones, even across generations [3-5]. Post-traumatic stress disorder is mostly recognized as the mental health burden; however, during conflict there is also significant disability from common mental health problems such as depression, anxiety, and substance misuse. From the Somalian conflict, these have been linked with the poverty associated with economic fragmentation and with a reduction of basic security functions and safety [6]. The link between armed conflict and the production and trafficking of illicit drugs has been noted in the literature, and recent research indicates a link between lootable resources, including opioids, and conflict duration [7]. As 2020 approaches, the conflict in Ukraine shifts to the emerging issues with substance uses and growing concern for mental health issues among the internally displaced population. As noted in a systematic review by Horyniak and colleagues (2016), forced migrants have commonly witnessed and personally experienced pre- and post-migration stress and trauma, including loss of homes and livelihoods, violence, and family separation [8]. Among this population, the prevalence of mental health disorders, specifically depression and post-traumatic stress disorder, are particularly high due to this lived experience [9-11]. 
In past studies, comorbidity between mental health and substance use disorders has been well documented in the general population [12-14]. An emerging literature has begun on substance use as a coping mechanism to document comorbidity among forced migrant populations [15-17].

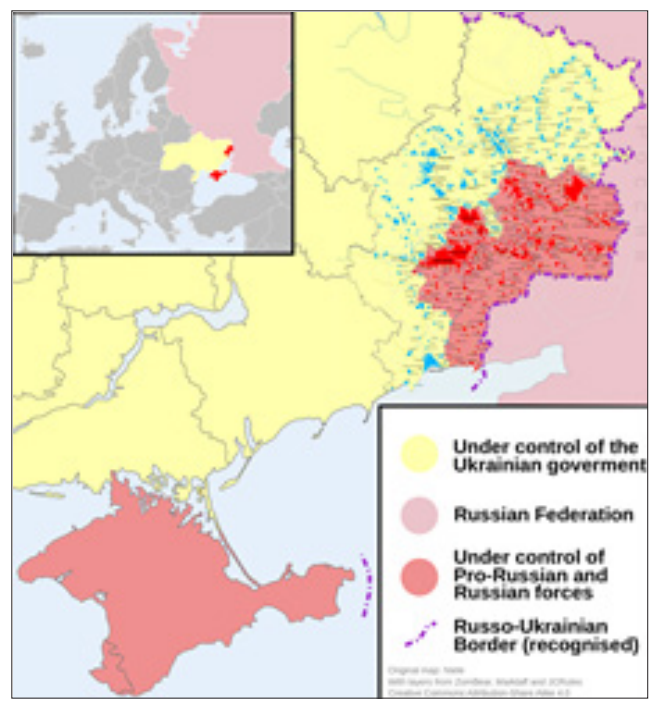

Figure 1: Current map of UKRAINE since the 2014 conflict.

Also, forced migrants experience acculturation challenges, the process of cultural and psychological change that follows contact with a culture other than one's own [18]. It has been hypothesized that migrants who are highly engaged in the host culture ('assimilation') may engage in substance use and addiction in order to adhere to mainstream norms and gain acceptance in their new communities [18-20]. Acculturation is an especially important factor for younger migrants, whose experiences are compounded by intergenerational conflict, and peer pressure as found in previous studies among Sudanese and Latino adolescents [19-23]. For example, in a study among ninth-grade adolescents, low levels of interest in maintaining their native culture alongside low levels of participation in their new culture, often due to discrimination and exclusion, has been associated with substance use [24]. Additionally, forced migrants, commonly experience social and economic inequality, marginalization and discrimination [25-28]. These factors have been shown to be important determinants of health, and could contribute to feelings of stress and powerlessness, which may contribute to substance use [29-31]. In addition, forced migrants could be exposed to illicit drugs as well through their residence in disadvantaged neighborhoods where drugs may be readily available leading to increased morbidity and mortality $[32,33]$. As a contributing factor, the HIV outbreak in Ukraine has spread throughout the nation. According to Public Health Center of the Ministry of Health of Ukraine, Ukraine continues to have high rates of HIV infection in Eastern Europe and Central and Eastern Asia [34]. According to the Ukrainian Center for Socially Dangerous Disease Control of the Ministry of Health of Ukraine, 25\% of all Ukrainian people suffering from HIV prior to the beginning of the armed conflict were living in the Donbass area [35]. Prior to the conflict, the services to HIV-infected and high-risk groups of population for HIV infection in Donetsk and Lugansk regions included one of the largest networks of health facilities and nongovernmental organizations. Currently, little is known on how much of this network is still functioning after the conflict and how much of the epidemic is fully controlled. According to Public Health Center of Ministry of Health of Ukraine, "only every second HIVpositive person is aware of his or her positive status and applies to a medical institution" and cases of parent-to-child transmissions have not decreased [34]. As a consequence of increased substance and alcohol uses and addictions in Ukraine, the Ukrainian Monitoring and Medical Center on Drugs and Alcohol (UMMCDA) was established in 2015 as a government agency within the Ministry of Health of Ukraine. This Center leads activities related to monitoring the circulation of opioid medicines, illicit drugs, other psychotropic substances and precursors in Ukraine [36].

\section{Conclusion}

The understanding of substance addiction among the conflict zones in Ukraine especially among the forced migrants remains limited. Past and current research suggest a need to integrate substance use prevention and treatment into services offered to veterans, internally displaced peoples, and civilian survivors. Efforts to develop and evaluate interventions to reduce substance use and related harms are needed. Further funding and research on substance and alcohol addiction from the 2014-2019 Ukrainian conflict should be examined. Are people from fragile states and conflict zones more susceptible to co-morbidity with substance abuse and addiction?.

\section{References}

1. OHCHR (2019) Office of the United Nations High Commissioner for Human Rights Report on the human rights situation in Ukraine. 
2. North Atlantic Treaty Organization (2018) Environmental health and security in Ukrainian Conflict Zones (SPS.ARW.G5432 2018).

3. Srinivasa Murthy R (2007) Mass violence and mental health--Recent epidemiological findings. International Review of Psychiatry 19(3): 183192.

4. Betancourt TS, Thomson D, Vander Weele TJ (2018) War-related traumas and mental health across generations. JAMA psychiatry 75(1): 5-6.

5. Rozanov V, Frančišković T, Marinić I, Macarenco MM, Letica-Crepulja M, et al. (2019) Mental health consequences of war conflicts. In: Javed A \& Fountoulakis K (Eds.), Advances in Psychiatry, pp. 281-304.

6. Bhui K, Warfa N (20.07) Drug consumption in conflict zones in Somalia. PLoS medicine 4(12): e354.

7. Cornell SE (2007) Narcotics and armed conflict: Interaction and implications. Studies in Conflict \& Terrorism 30(3): 207-227.

8. Horyniak D, Melo JS, Farrell RM, Ojeda VD, Strathdee SA (2016) Epidemiology of substance use among forced migrants: A global systematic review. PLoS one 11(7): e0159134.

9. Porter M, Haslam N (2005) Predisplacement and postdisplacement factors associated with mental health of refugees and internally displaced persons: A meta-analysis. Journal of the American Medical Association 294(5): 602-612.

10. Steel Z, Chey T, Silove D, Marnane C, Bryant RA, et al. (2009) Association of torture and other potentially traumatic events with mental health outcomes among populations exposed to mass conflict and displacement: A systematic review and meta-analysis. Journal of the American Medical Association 302(5): 537-549.

11. Fazel M, Wheeler J, Danesh J (2005) Prevalence of serious mental disorder in 7000 refugees resettled in western countries: a systematic review. Lancet 365(9467): 1309-1314.

12. Schuckit MA (2006) Comorbidity between substance use disorders and psychiatric conditions. Addiction 101: 76-88.

13. Liang W, Chikritzhs T, Lenton S (2011) Affective disorders and anxiety disorders predict the risk of drug harmful use and dependence. Addiction 106(6): 1126-1134.

14. Swendsen J, Conway KP, Degenhardt L, Glantz M, Jin R, Merikangas KR, et al. (2010) Mental disorders as risk factors for substance use, abuse and dependence: Results from the 10-year follow-up of the national comorbidity survey. Addiction 105(6): 1117-1128.

15. Posselt M, Galletly C, de Crespigny C, Procter N (2013) Mental health and drug and alcohol comorbidity in young people of refugee background: A review of the literature. Mental Health and Substance Use 7: 19-30.

16. Kozaric-Kovacic D, Ljubin T, Grappe M (2000) Comorbidity of posttraumatic stress disorder and alcohol dependence in displaced persons. Croatian Medical Journal 41(2): 173-178.

17. Brune M, Haasen C, Yagdiran O, Bustos E (2003) Treatment of drug addiction in traumatised refugees: A case report. Eur Addict Res 9(3): 144- 146.

18. Berry JW (1997) Immigration, acculturation and adaptation. Applied Psychology 46(1): 5-34.
19. Buchanan RL, Smokowski PR (2009) Pathways from acculturation stress to substance use among Latino adolescents. Substance Use \& Misuse 44(5): 740-762.

20. Blanco C, Morcillo C, Alegría M, Dedios MC, Fernández -Navarro P, et al. (2013) Acculturation and drug use disorders among Hispanics in the U.S. Journal of Psychiatric Research 47(2): 226-232.

21. Reid G, Aitken C, Beyer L, Crofts N (2001) Ethnic communities' vulnerability to involvement with illicit drugs. Drugs: education, prevention and policy 8: 359-374.

22. Poppitt G, Frey R (2007) Sudanese adolescent refugees: Acculturation and acculturative stress. Australian Journal of Guidance and Counselling 17(2): 160-181.

23. Milner K, Khawaja NG (2010) Sudanese refugees in Australia: The impact of acculturation stress. Journal of Pacific Rim Psychology 4(1): 19-29.

24. Fosados R, McClain A, Ritt-Olson A, Sussman S, Soto D, et al. (2007) The influence of acculturation on drug and alcohol use in a sample of adolescents. Addictive Behaviors 32(12): 2990-3004

25. Colic-Peisker V, Tilbury F (2007) Integration into the Australian labour market: The experience of three "visibly different" groups of recently arrived refugees. International Migration 45(1): 59-85.

26. Carter TS, Osborne J (2009) Housing and neighbourhood challenges of refugee resettlement in declining inner city neighbourhoods: a winnipeg case study. Journal of Immigrant \& Refugee Studies 7(3): 308-327.

27. Capps R, Newland K, Fratzke S, Groves S, Auclair G, Fix M, et al. (2015) The integration outcomes of U.S. refugees: Successes and challenges. Migration Policy Institute, Washington, USA.

28. Fozdar F, Hartley L (2014) Civic and ethno belonging among recent refugees to Australia. Journal of Refugee Studies 27(1): 126-144.

29. Viruell-Fuentes EA, Miranda PY, Abdulrahim S (2012) More than culture: Structural racism, intersectionality theory, and immigrant health. Social Science \& Medicine 75(12): 2099-2106.

30. Wilkinson RG (2006) Ourselves and others-for better or worse: social vulnerability and inequality In: Marmot M, Wilkinson RG, (editors.), Social Determinants of Health. ( $2^{\text {nd }}$ edn), Oxford University Press, Oxford, UK.

31. Frohlich KL, Potvin L (2008) Transcending the known in public health practice: The inequality paradox: the population approach and vulnerable populations. Am J Public Health 98(2): 216-221.

32. Karriker-Jaffe KJ (2011) Areas of disadvantage: A systematic review of effects of area-level socioeconomic status on substance use outcomes. Drug Alcohol Rev 30(1): 84-95.

33. Livingston M (2012) The social gradient of alcohol availability in Victoria, Australia. Aust N Z J Public Health 36(1): 41-47.

34. (2019) Public Health Center of the Ministry of Health (2019) HIV/AIDS.

35. International HIV/AIDS and TB Institute (2017) How has the conflict in the donbas contributed to the HIV situation in Ukraine?

36.(2016) European monitoring centre for drugs and drug addiction Ukraine country overview. 